\title{
TINJAUAN KAPASITAS, HAMBATAN SAMPING DAN KINERJA JALAN PADA KAWASAN KOMERSIAL DAN KAWASAN PENDIDIKAN DI KOTA MATARAM
}

\author{
ROHANI $^{1)}$, I DEWA MADE ALIT KARYAWAN ${ }^{2)}$ JUNIATI HAPSAH $^{3)}$ \\ Jurusan Teknik Sipil Fakultas Teknik Universitas Mataram \\ e-mail :rohani@unram.ac.id
}

\begin{abstract}
ABSTRAK
Kinerja lalu lintas kawasan komersial dan kawasan pendidikan dipengaruhi oleh volume lalu lintas dan kapasitas jalan. Salah satu dampak terhadap kinerja jalan adalah hambatan samping. Tujuan dari penelitian ini adalah untuk mengetahui volume lalu lintas, hambatan samping, kapasitas dan kinerja jalan kawasan komersial dan pendidikan berdasarkan derajat kejenuhan. Menganalisa dan mengkaji hubungan hambatan samping terhadap volume, kapasitas dan derajat kejenuhan.

Penelitian ini menggunakan data sekunder dari penelitian sebelumnya. Jalan Dr Wahidin dan Jalan Panca Usaha sebagai jalan kawasan komersial. Jalan Gajah Mada dan Jalan Bung Karno sebagai jalan kawasan pendidikan.

Hasil analisis menunjukkan bahwa jalan pada kawasan komersial memiliki hambatan samping, volume dan derajat kejenuhan yang tinggi serta kapasitas yang rendah dengan tingkat pelayanan jalan E. Sedangkan jalan pada kawasan pendidikan memiliki volume yang rendah, kapasitas yang tinggi dan derajat kejenuhan yang rendah dengan tingkat pelayanan jalan C. Dari hasil analisis regresi, hambatan samping berpengaruh sangat signifikan terhadap volume, kapasitas dan derajat kejenuhan. Dapat dilihat dari nilai (r) berada pada rentang $0,7<\mathrm{r}<0,9$ menunjukkan korelasi yang kuat dan $0,9<\mathrm{r}<1$ menunjukkan korelasi yang sangat kuat.
\end{abstract}

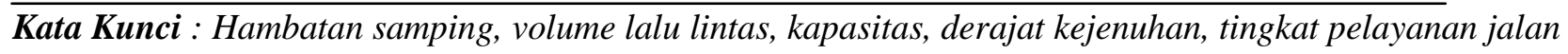

\section{ABSTRACT}

The traffic performance of the commercial and educational areas is influenced by the volume flow and road capacity. One of the impacts on traffic performance is side friction. The purpose of this study was to compare traffic flow, side friction, road capacity and performance in the commercial and educational areas by degree of saturation. Analyze and assess the relationship between side constraints on volume, capacity and degree of saturation.

This study uses secondary data from previous studies. Jalan Dr. Wahidin and Jalan Panca Usaha as commercial area roads. Jalan Gajah Mada and Jalan Bung Karno as educational areas.

The results of the analysis show that the roads in the commercial area have side barriers, high volume and degree of saturation and low capacity. The level of Service E. Meanwhile, education area roads have low volume, high capacity and low degree of saturation. The level of service C. From the regression analysis, the side friction has a very significant effect on the volume, capacity and degree of saturation. It can be seen from the value $(r)$ in the range $0.7<r<0.9$ indicating a strong correlation and $0.9<r<1$ indicating a very strong correlation.

Keywords: Side friction, traffic flow, capacity, degree of saturation, level of service

\section{PENDAHULUAN}

Jalan raya Kota Mataram khususnya sepanjang Jalan Dr Wahidin dan Jalan Panca Usaha merupakan ruas jalan yang dijadikan sebagai kawasan pusat perekonomian. Disepanjang ruas jalan Dr. Wahidin terdapat banyak pertokoan dan rumah makan yang tidak memiliki lahan parkir yang cukup sehingga banyak kendaraan parkir di bahu jalan bahkan di badan jalan. Sedangkan di sepanjang ruas Jalan Panca Usaha terdapat banyak pertokoan, rumah makan, hotel dan perkantoran yang tidak memiliki lahan parkir yang 
cukup sehingga pada jam-jam tertentu sering terjadi kemacetan.

Jalan Gajah Mada dan Jalan Bung Karno merupakan jalan dengan kondisi lalu lintas yang cukup ramai. Pada ruas Jalan Gajah Mada terdapat dua perguruan tinggi yaitu Universitas Muhamadiyah Mataram dan Universitas Islam Negeri Mataram. Selain itu, pada ruas Jalan Gajah Mada juga terdapat pasar dan pertokoan yang tidak memiliki lahan parkir yang cukup sehingga banyak kendaraan terparkir pada bahu jalan. Pada jam-jam tertentu saat mahasiswa pergi dan pulang kuliah arus lalu lintas cenderung padat. Sedangkan ruas jalan Bung Karno terdapat Rumah Sakit Kota Mataram, Sekolah Tinggi Teknik Lingkungan Mataram dan SMPN 7 Mataram. Permasalahan lalu lintasnya hampir sama dengan ruas Jalan Gajah Mada.

Berdasarkan penelitian pada ruas Jalan Dr. Wahidin, Jalan Panca Usaha, Jalan Gajah Mada dan Jalan Bung Karno menunjukkan perbedaan hasil analisis kinerja ruas jalan. Oleh karena itu peneliti bermaksud untuk melakukan studi literatur dengan membandingkan dua tipe kawasan lalu lintas yang berbeda yaitu kawasan komersial dan kawasan pendidikan. Studi literatur dengan judul "Tinjauan Kapasitas, Hambatan

Samping dan Kinerja Jalan Pada Kawasan Komersial dan Kawasan Pendidikan" studi kasus pada ruas Jalan Dr Wahidin dan Jalan Panca Usaha sebagai kawasan komersial dan ruas Jalan Gajah Mada Dan Jalan Bung Karno sebagai kawasan pendidikan.

\section{Rumusan Masalah}

Adapun rumusan masalah dalam penelitian ini sebagai berikut:

1. Bagaimana perbandingan volume lalu lintas, hambatan samping dan kapasitas jalan kawasan komersial dan kawasan pendidikan.

2. Bagaimana analisis dan kajian hubungan hambatan samping terhadap volume kapasitas dan derajat kejenuhan.

3. Bagaimana analisis perbedaan kinerja jalan pada kawasan komersial dan kawasan pendidikan berdasarkan perbandingan derajat kejenuhan

\section{Tujuan Penelitian}

Tujuan dari penelitian ini adalah sebagai berikut :

1. Mengetahui perbandingan volume lalu lintas, hambatan samping dan kapasitas jalan kawasan komersial dan kawasan pendidikan.

2. Menganalisa dan mengkaji hubungan hambatan samping terhadap volume kapasitas dan derajat kejenuhan.

3. Menganalisa perbedaan kinerja jalan pada kawasan komersial dan kawasan pendidikan berdasarkan perbandingan derajat kejenuhan.

\section{METODE PENELITIAN}

Data yang digunakan berupa data sekunder. Adapun sumber data penelitian terdahulu yang dipakai dalam penelitian ini yaitu:

1. Data dari penelitian Octavia (2020).

2. Data dari penelitian Aryana (2015).

3. Data dari penelitian Seftiana (2019).

4. Data dari penelitian Prasetyo (2017).

\section{Analisis Data}

1. Metode Analisis Deskriptif Kualitatif. Untuk mengumpulkan dan menyusun data, kemudian melakukan analisis terhadap data tersebut.

2. Analisis Komparatif. Untuk membandingkan hubungan antara hambatan samping terhadap volume, kapasitas dan derajat kejenuhan.

3. Analisa Regresi. Untuk mengetahui besar pengaruh yang dihasilkan dari analisis hambatan samping. Analisa regresi yang digunakan adalah analisa regresi yang memiliki hubungan atau keterkaitan yang paling signifikan dan memiliki nilai korelasi tertinggi. Analisa regresi dapat memprediksi perilaku dari variabel terikat dengan menggunakan data dari variabel bebas.

a. Variabel bebas adalah hambatan samping.

b. Variabel terikat adalah volume, kapasitas dan derajat kejenuhan.

4. Analisa Koefisien Determinasi, menjelaskan seberapa besar pengaruh yang diberikan oleh hambatan samping terhadap volume, kapasitas dan derajat kejenuhan.

5. Analisa Koefisien Korelasi, analisa ini dilakukan untuk mengetahui keeratan hubungan hambatan samping terhadap volume, kapasitas dan derajat kejenuhan. 


\section{Volume Lalu Lintas}

Sesuai MKJI 1997 Volume lalu lintas didefinisikan sebagai jumlah kendaraan yang melalui titik pada jalan per satuan waktu, dinyatakan dalam kend/jam (Qkend), smp/jam (Qsmp).

$$
V=N / T
$$

dimana :

$\mathrm{V}=$ Volume (kend/jam)

$\mathrm{N}=$ Jumlah kendaraan (kend)

$\mathrm{T}=$ Waktu pengamatan (jam)

\section{Kapasitas}

Kapasitas jalan adalah kemampuan maksimum jalan untuk dapat melewatkan kendaraan yang akan melintas pada suatu jalan raya, baik itu untuk satu arah maupun dua arah pada jalan satu jalur maupun banyak jalur pada satuan waktu tertentu,

dimana:

$$
\mathrm{C}=\mathrm{C}_{0} \times \mathrm{FC}_{\mathrm{W}} \times \mathrm{FC}_{\mathrm{SP}} \times \mathrm{FC}_{\mathrm{SF}} \times \mathrm{FC}_{\mathrm{CS}}
$$

$\mathrm{C} \quad=$ Kapasitas ( $\mathrm{smp} / \mathrm{jam})$

$\mathrm{C}_{0} \quad=$ Kapasitas dasar (smp/jam)

$\mathrm{FC}_{\mathrm{W}}=$ Faktor penyesuaian lebar jalur lalu-lintas

$\mathrm{FC}_{\mathrm{SP}}=$ Faktor penyesuaian pemisahan arah

$\mathrm{FC}_{\mathrm{SF}}=$ Faktor penyesuaian hambatan samping

$\mathrm{FC}_{\mathrm{CS}}=$ Faktor penyesuaian ukuran kota

\section{Derajat Kejenuhan}

Derajat kejenuhan (DS) didefinisikan sebagai rasio arus lalu lintas terhadap kapasitas. Digunakan sebagai faktor utama dalam penentuan tingkat kinerja simpang dan segmen jalan

$$
\mathrm{DS}=\mathrm{Q} / \mathrm{C}
$$

dimana :

DS $=$ Derajat Kejenuhan

$\mathrm{Q}=$ Arus Lalu Lintas (smp/jam)

$\mathrm{C}=$ Kapasitas $(\mathrm{smp} / \mathrm{jam})$

\section{Hambatan Samping}

Menurut (MKJI) 1997, hambatan samping adalah dampak terhadap kinerja lalu lintas dari aktivitas samping segmen jalan, yaitu pejalan kaki, angkutan umum dan kendaraaan lain yang berhenti dan parkir, kendaraan yang keluar masuk dari/ke lahan samping/sisi jalan dan arus kendaraan yang bergerak lambat.

Tabel 1. Kelas Hambatan Samping Untuk Jalan Perkotaan

\begin{tabular}{|c|c|c|c|}
\hline $\begin{array}{c}\text { Kelas hambatan } \\
\text { samping (SFC) }\end{array}$ & Kode & $\begin{array}{c}\text { Jumlah berbobot kejadian } \\
\text { per 200 m (dua sisi) }\end{array}$ & Kondisi Khusus \\
\hline Sangat rendah & VL & $<100$ & $\begin{array}{c}\text { Daerah pemukiman; jalan dengan jalan } \\
\text { samping }\end{array}$ \\
\hline Rendah & L & $100-299$ & $\begin{array}{c}\text { Daerah pemukiman ; beberapa kendaraan umum } \\
\text { dsb }\end{array}$ \\
\hline Sedang & M & $300-499$ & Daerah industri ; bebrapa toko disisi jalan \\
\hline Tinggi & H & $500-899$ & Daerah komersial aktivitas disisi jalan tinggi \\
\hline Sangat tinggi & VH & $>900$ & $\begin{array}{c}\text { Daerah komersial dengan aktivitas pasar di } \\
\text { samping jalan }\end{array}$ \\
\hline
\end{tabular}

\section{Analisa Statistik}

Sumber : Manual Kapasitas Jalan Indonesia (MKJI), 1997

\section{Analisis Regresi:}

1. Analisis regresi linier

Model analisis regresi linear sederhana dapat ditulis dengan persamaan :

$$
Y_{i}=a+b X
$$

2. Analisis regresi non linier

Model persamaan regresi non linier dapat dibedakan menjadi sebagai berikut (Sudjana, 1992) :

1) Regresi polynomial

$$
Y=a+b X+c X^{2} \text { (fungsi kuadratik) }
$$


2) Regresi eksponensial

$$
Y=a e^{b x}
$$

\section{Koefisien Korelasi}

$$
r=\frac{n \sum X_{i} Y_{i}-\left(\sum X_{i}\right)\left(\sum Y_{i}\right)}{\sqrt{\left\{n \sum X_{i}^{2}-\left(\sum X_{i}\right)^{2}\right\}\left\{n \sum Y_{i}^{2}-\left(\sum Y_{i}\right)^{2}\right\}}}
$$

Untuk memudahkan melakukan interpretasi mengenai kekuatan hubungan antara dua variabel diberikan kriteria sebagai berikut (Sudjana, 2013) :

- $\quad$ Nilai $r=0$ (tidak ada hubungan)

- $0<\mathrm{r}<0,2$ (sangat lemah)

- $0,2<\mathrm{r}<0,4$ (lemah)

- $0,4<\mathrm{r}<0,7$ (sedang)

- $0,7<\mathrm{r}<0,9$ (kuat)

- $0,9<\mathrm{r}<1$ (sangat kuat)

\section{Koefisien Determinasi}

$$
r^{2}=\frac{b\left\{n \sum X_{i} Y_{i}-\left(\sum X_{i}\right)\left(\sum Y_{i}\right)\right\}}{n \sum Y_{i}^{2}-\left(\sum Y_{i}\right)^{2}}
$$

\section{HASIL DAN PEMBAHASAN}

\section{Perbandingan Volume Kawasan Komersial dan Kawasan Pendidikan}

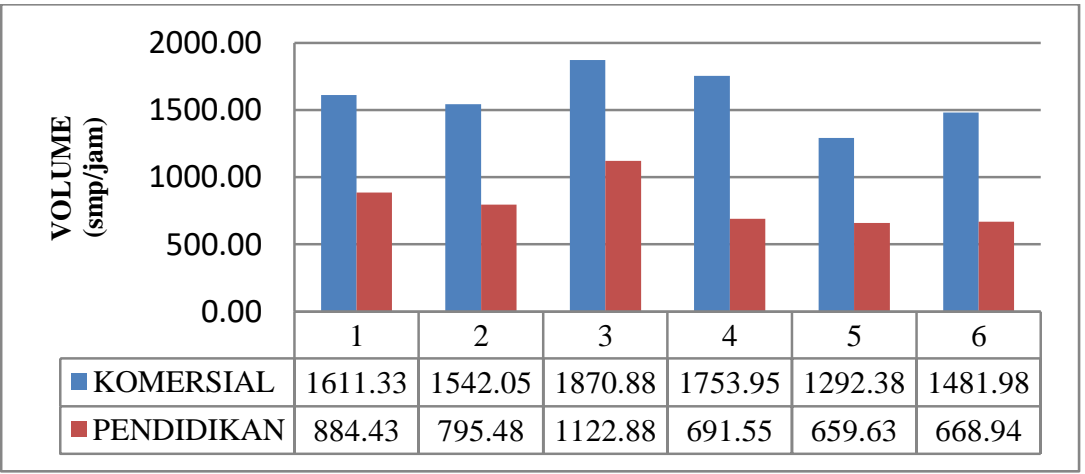

Gambar 1. Perbandingan Volume Lalu Lintas Kawasan Komersial dan Pendidikan

Kawasan komersial memiliki volume kendaraan tertinggi baik ketika pada hari kerja maupun hari libur. Hal ini sesuai dengan pernyataan Tamin (2000) bahwa pemanfaatan lahan kawasan komersial merupakan pemanfaatan lahan dengan volume pergerakan tertinggi karena memiliki karekteristik banyaknya aktivitas yang berlangsung didalamnya.

Perbedaan volume pergerakan lalu lintas yang signifikan pada jalan kawasan komersial dan kawasan pendidikan disebabkan karena banyaknya aktivitas pada jam puncak masing-masing kawasan. Hal ini sesuai dengan teori yang dikemukakan oleh Tamin (2000) bahwa setiap pemanfaatan lahan memiliki karakteristik aktivitas masing-masing sehingga terjadi perbedaan waktu dalam volume pergerakan tertinggi yang dihasilkan. Pada kawasan komersial yaitu Jalan Dr. Wahidin dan Jalan Panca Usaha, waktu puncak terjadi pada pagi dan sore hari. Pada waktu pagi penduduk datang untuk memulai aktivitasnya seperti kegiatan jual beli dan pada sore hari penduduk selesai beraktivitas dan kembali ke tempat tinggalnya masing-masing. Tingginya volume pergerakan pada jalan kawasan komersial dikarenakan perputaran pergerakan antar pedagang dan pembeli yang berdatangan berlangsung sangat cepat (Anggraeni, 2018). Sedangkan pada kawasan pendidikan yaitu Jalan Gajah Mada dan Jalan Bung Karno, waktu puncak terjadi pada pagi dan siang hari untuk aktivitas mengantar dan menjemput anak sekolah bagi orang tua dan pulang pergi kuliah bagi mahasiswa. 


\section{Perbandingan Hambatan Samping Kawasan Komersial dan Pendidikan}

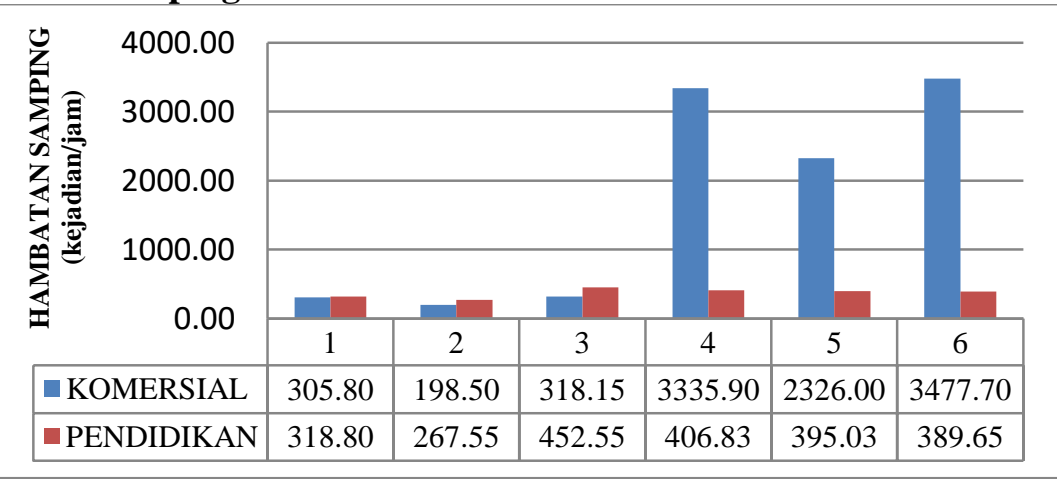

\section{Gambar 2 Perbandingan Hambatasan Samping Lalu Lintas Kawasan Komersial dan Pendidikan}

Hambatan samping tertinggi terjadi pada kawasan komersial di ruas Jalan Panca Usaha saat hari kerja (hari senin) sebesar 3477,70 kejadian/jam. Kelas hambatan samping pada ruas Jalan Panca Usaha termasuk kelas sangat tinggi (>900 kejadian). Berbeda dengan ruas jalan Dr. wahidin, hambatan samping tertinggi sebesar 318,15 kejadian/jam sehingga termasuk dalam kelas hambatan samping sedang (300 - 499 kejadian). Rendahnya hambatan samping Jalan Dr. Wahidin dipengaruhi oleh rendahnya frekwensi pejalan kaki, kendaraan yang berhenti, kendaraan yang keluar-masuk jalan dan kendaraan lambat (Octavia, 2020)

Hambatan samping kawasan pendidikan pada ruas Jalan Gajah Mada dan Bung Karno saat hari kerja lebih tinggi daripada ruas jalan Dr. Wahidin. Hal tersebut disebabkan karena pada kawasan pendidikan dimanfaatkan sebagai rumah tinggal, kos-kosan dan tempat usaha terutama bagi PKL yang menjajakan dagangannya pada sisi kiri-kanan jalan. Seperti yang dikemukakan oleh Turyanto (2014) adanya perkembangan guna lahan pada kawasan pendidikan menyebabkan peningkatan hambatan samping. Hambatan samping untuk jalan kawasan pendidikan termasuk pada kelas hambatan samping sedang (300 499 kejadian).

Tingginya hambatan samping pada ruas Jalan Panca Usaha hingga termasuk pada kelas sangat tinggi (VH) disebabkan karena pada sepanjang ruas jalan tersebut berderet toko-toko, hotel dan rumah makan baik disisi kanan maupun kiri jalan. Hambatan samping yang paling mendominasi adalah kendaraan yang keluarmasuk (EEV) jalan (Aryana,2015).

\section{Perbandingan Kapasitas Kawasan Komersial Dan Kawasan Pendidikan}

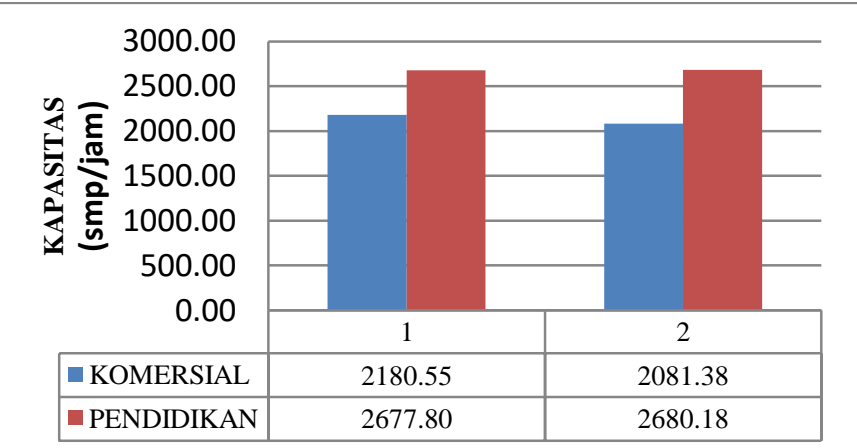

\section{Gambar 3 Perbandingan Kapasitas Kawasan Komersial dan Kawasan Pendidikan}

Kapasitas pada kawasan pendidikan lebih tinggi dibandingkan dengan kawasan komersial. Hal tersebut disebabkan pada kawasan komersial terutama Jalan Panca Usaha memiliki hambatan samping yang tinggi sehingga kapasitas jalan rendah. Selain hambatan samping perbedaan kapasitas yang signifikan pada jalan kawasan pendidikan dan kawasan komersial juga dipengaruhi oleh tipe jalan dan kondisi geometrik jalan. Dimana jalan pada kawasan komersial yaitu Jalan Dr. Wahidin merupakan jalan dengan tipe dua lajur dua arah tak terbagi (2/2UD) dan lebar jalur sebesar 6.1 meter (Octavia, 2020). Sedangkan Jalan Panca Usaha merupakan jalan dengan tipe dua lajur satu arah (2/1UD) dan lebar jalur sebesar 6.5 meter (Aryana, 2015). Untuk jalan kawasan pendidikan yaitu Jalan Gajah Mada merupakan jalan dengan tipe empat lajur dua arah terbagi (4/2D) dan lebar jalur sebesar 6 meter pada masing-masing arah (Seftiana, 2019). Sedangkan Jalan Bung Karno merupakan jalan dengan tipe empat lajur dua arah terbagi (4/2D) dan lebar jalur sebesar 7 meter pada masing-masing arah (Prasetyo, 2017). 


\section{Hubungan Hambatan Samping Terhadap Volume Lalu Lintas}

1. Hubungan Hambatan Samping Terhadap Volume Lalu Lintas Kawasan Komersial

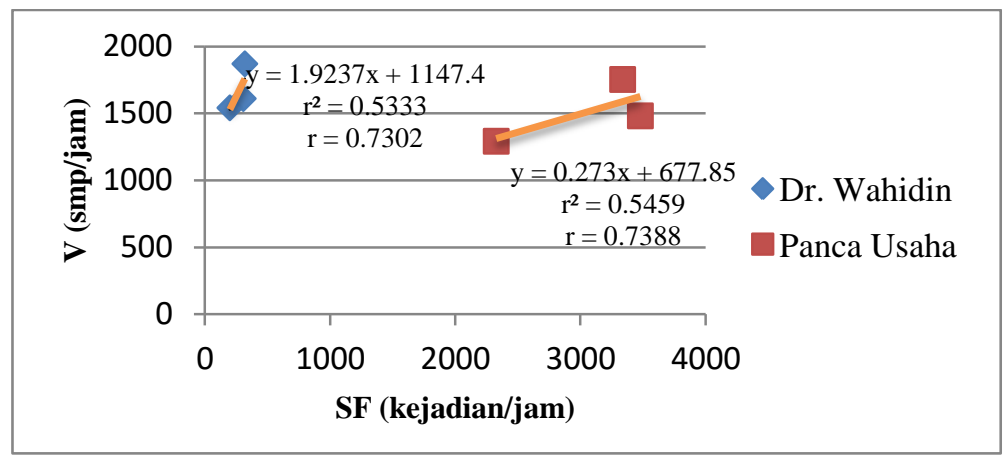

\section{Gambar 4 Grafik Hubungan Hambatan Samping Terhadap Volume Kawasan Komersial}

Hambatan samping (X) secara simultan berpengaruh terhadap variabel volume lalu lintas (Y) sebesar $53,33 \%$ pada Jalan Dr. Wahidin dan 54,59 \% pada Jalan Panca Usaha. Hal tersebut diperkuat dengan nilai koefisien korelasi (r) yang dihasilkan pada Jalan Dr. Wahidin dan Jalan Panca Usaha berturut-turut sebesar 0,7302 dan 0,7388. Maka berdasarkan nilai korelasi tersebut dapat diketahui bahwa hubungan antara hambatan samping dengan volume lalu lintas kedua jalan pada kawasan komersial menunjukkan pengaruh hubungan yang kuat. Diperoleh hubungan dan nilai korelasi yang positif antara hambatan samping dan volume lalu lintas. Artinya semakin tinggi hambatan samping maka volume kendaraan semakin besar.

2. Hubungan Hambatan Samping Terhadap Volume Lalu Lintas Kawasan Pendidikan

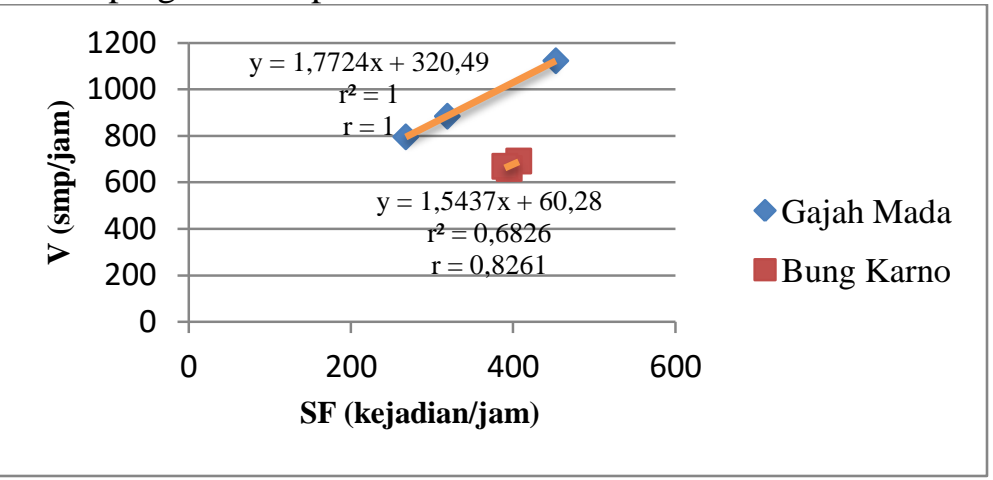

\section{Gambar 5 Grafik Hubungan Hambatan Samping Terhadap Volume Kawasan Pendidikan}

Hambatan samping (X) secara simultan berpengaruh terhadap variabel volume lalu lintas (Y) sebesar $100 \%$ pada Jalan Gajah Mada dan 68,26 \% pada Jalan Bung Karno. Hal tersebut diperkuat dengan nilai korelasi untuk Jalan Gajah mada sebesar 1 dan Jalan Bung Karno sebesar 0,8261. Berdasarkan nilai korelasi yang diperoleh dapat diketahui Jalan Gajah Mada menunjukkan pengaruh hubungan yang sangat kuat/sempurna sedangkan Jalan Bung Karno menunjukkan pengaruh hubungan yang kuat. Kedua jalan pada kawasan pendidikan menghasilkan nilai korelasi yang positif antara hambatan samping dengan volume lalu lintas. Artinya semakin tinggi hambatan samping maka volume yang dihasilkan semakin besar.

\section{Hubungan Hambatasan Samping Terhadap Kapasitas Jalan}

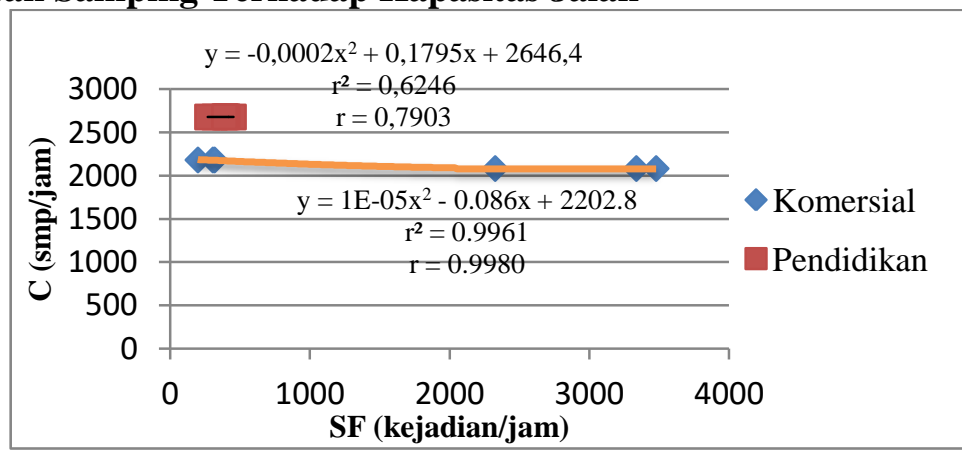

Gambar 6. Grafik Hubungan Hambatasan Samping Terhadap Kapasitas Jalan Kawasan Komersial dan Pendidikan 
Hambatan samping (X) secara simultan berpengaruh terhadap variabel kapasitas jalan (Y) kawasan komersial sebesar 99,61\% dan kawasan pendidikan sebesar 62, 46\%. Hal tersebut diperkuat dengan nilai koefisien korelasi yang diperoleh pada kawasan komersial dan pendidikan sebesar 0,9980 dan 0,7903. Berdasarkan nilai korelasi menunjukkan pada kawasan komersial dan kawasan pendidikan menghasilkan hubungan korelasi yang kuat.

Grafik kawasan pendidikan menunjukan tingginya hambatan samping diikuti oleh tinggnya kapasitas. Hambatan samping pada kawasan pendidikan termasuk pada kelas hambatan samping sedang. Sementara jalan pada kawasan pendidikan merupakan jalan dengan tipe empat lajur dua arah terbagi (4/2 D). Hambatan samping sedang dan jalur pergerakan kendaraan lebih besar sehingga menghasilkan kapasitas jalan yang tinggi. Sedangkan pada grafik kawasan komersial dapat diketahui bahwa semakin tinggi hambatan samping, maka kapasitasnya semakin rendah. Jalan pada kawasan komersial merupakan jalan dengan tipe dua arah (2/2UD) pada Jalan Dr. Wahidin dan dua lajur satu arah (2/1UD) pada Jalan Panca Usaha. Adanya hambatan samping yang tinggi dan jalur pergerakan kendaraan yang lebih kecil dibandingkan jalan kawasan pendidikan mempengaruhi penurunan kapasitas jalan.

\section{Derajat Kejenuhan}

Tabel 3 Perhitungan Derajat Kejenuhan Jalan Kawasan Komersial dan Pendidikan

\begin{tabular}{|c|c|c|c|c|c|}
\hline \multirow[t]{2}{*}{ Hari } & \multirow[t]{2}{*}{ Jalan } & \multirow[t]{2}{*}{ Kawasan } & V Rata-Rata & C Rata-Rata & DS \\
\hline & & & (Smp/jam) & (smp/jam) & $(\mathrm{V} / \mathrm{C})$ \\
\hline Sabtu & \multirow{3}{*}{$\begin{array}{c}\text { Dr. } \\
\text { Wahidin }\end{array}$} & \multirow{6}{*}{ Komersial } & 1611,3 & 2180,5 & 0,739 \\
\hline Minggu & & & 1542,1 & 2180,5 & 0,707 \\
\hline Senin & & & 1915,0 & 2180,5 & 0,878 \\
\hline Sabtu & \multirow{3}{*}{$\begin{array}{l}\text { Panca } \\
\text { Usaha }\end{array}$} & & 1754,0 & 2081,3 & 0,843 \\
\hline Minggu & & & 1292,4 & 2081,3 & 0,621 \\
\hline Senin & & & 1482,0 & 2081,3 & 0,712 \\
\hline Sabtu & \multirow{3}{*}{$\begin{array}{l}\text { Gajah } \\
\text { Mada }\end{array}$} & \multirow{6}{*}{ Pendidikan } & 884,4 & 2677,8 & 0,330 \\
\hline Minggu & & & 795,5 & 2677,8 & 0,297 \\
\hline Senin & & & 1122,9 & 2677,8 & 0,419 \\
\hline Selasa & \multirow{3}{*}{$\begin{array}{l}\text { Bung } \\
\text { Karno }\end{array}$} & & 691,5 & 2680,1 & 0,258 \\
\hline Jumat & & & 659,6 & 2680,1 & 0,246 \\
\hline Sabtu & & & 668,9 & 2680,1 & 0,250 \\
\hline
\end{tabular}

Sumber : Hasil perhitungan

\section{Hubungan Hambatan Samping Terhadap Derajat Kejenuhan}

1. Hubungan Hambatan Samping Terhadap Derajat Kejenuhan Kawasan komersial

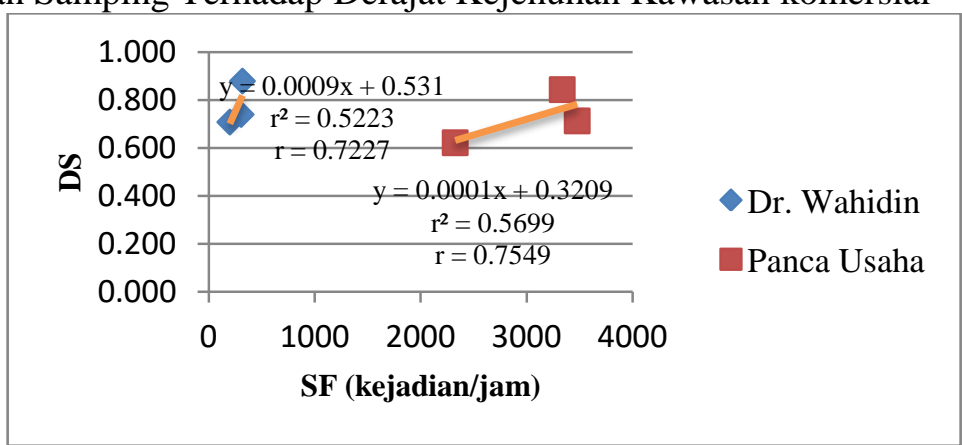

\section{Gambar 7 Grafik Hubungan Hambatan Samping Terhadap Derajat Kejenuhan Kawasan Komersial}

Pengaruh hambatan samping terhadap derajat kejenuhan Jalan Dr. wahidin sebesar 52,23\% dan sisanya dipengaruhi oleh faktor lain. Sedangkan pengaruh hambatan samping terhadap derajat kejenuhan Jalan Panca Usaha sebesar 56,99 \% dan sisanya dipengaruhi oleh faktor lain. Keterkaitan hubungan antara variabel hambatan samping dengan variabel derajat kejenuhan kawasan komersial dapat diketahui melalui nilai korelasi yang diperoleh dari grafik analisis regresi yang digunakan. Nilai korelasi yang diperoleh pada kawasan komersial di Jalan Dr. Wahidin sebesar 0,7227 dan Jalan Panca Usaha sebesar 0,7549. Artinya hubungan antara variabel hambatan samping dengan variabel derajat kejenuhan kedua jalan tersebut berkolerasi kuat. Kedua jalan pada kawasan komersial menghasilkan persamaan linear yang posistif. Artinya semakin tinggi hambatan samping maka derajat kejenuhan semakin besar. Besarnya nilai derajat kejenuhan kawasan komersial dipengaruhi oleh banyaknya volume dan rendahnya kapasitas jalan. 
2. Hubungan Hambatan Samping Terhadap Derajat Kejenuhan Kawasan Pendidikan

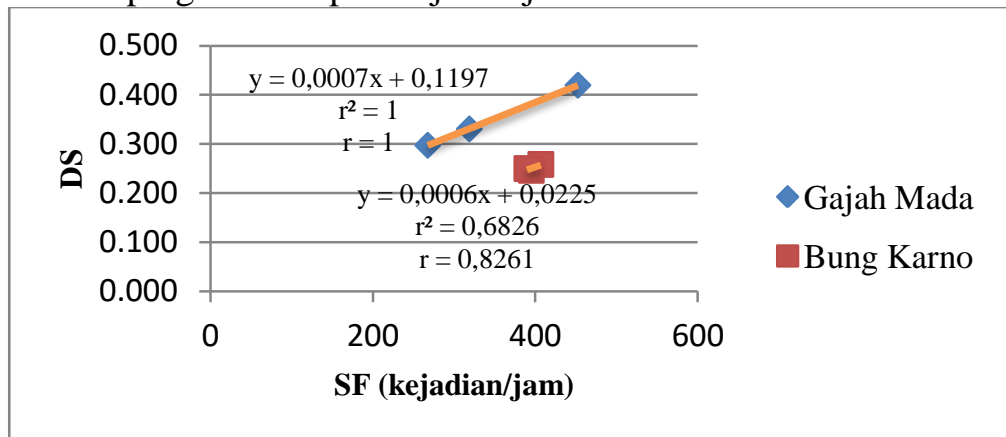

\section{Gambar 8 Grafik Hubungan Hambatan Samping Terhadap Derajat Kejenuhan Kawasan Pendidikan}

Pengaruh hambatan samping terhadap derajat kejenuhan pada Jalan Gajah Mada sebesar $100 \%$. Sedangkan pada Jalan Bung Karno sebesar 68,26 \% dan sisanya dipengaruhi oleh faktor lain. Keterkaitan hubungan antara variabel hambatan samping dengan variabel derajat kejenuhan kawasan pendidikan dapat diketahi melalui nilai korelasi yang diperoleh dari grafik regresi yang digunakan. Nilai korelasi yang dihasilkan pada kawasan pendidikan di Jalan Gajah Mada sebesar 1,0 dan Jalan Bung Karno sebesar 0,8261. Artinya besarnya hubungan antara variabel hambatan samping dengan variabel derajat kejenuhan pada Jalan Gajah Mada berkolerasi sangat kuat sedangkan pada Jalan Bung Karno berkorelasi kuat. Kedua jalan pada kawasan pendidikan menghasilkan persamaan linear yang positif. Artinya semakin tinggi hambatan samping maka derajat kejenuhan semakin besar.

\section{Analisis Kinerja Jalan Kawasan komersial dan Kawasan Pendidikan}

Tabel 3 Kinerja Jalan Kawasan Komersial dan Pendidikan

\begin{tabular}{|c|c|c|c|c|c|c|}
\hline \multirow[t]{2}{*}{ No } & \multirow[t]{2}{*}{ Jalan } & \multicolumn{2}{|c|}{$\begin{array}{c}\text { Kinerja jalan kawasan } \\
\text { komersial }\end{array}$} & \multirow[t]{2}{*}{ Jalan } & \multicolumn{2}{|c|}{$\begin{array}{c}\text { Kinerja jalan kawasan } \\
\text { pendidikan }\end{array}$} \\
\hline & & DS & TP & & DS & TP \\
\hline 1 & \multirow{3}{*}{$\begin{array}{c}\text { Dr. } \\
\text { Wahidin }\end{array}$} & 0,739 & C & \multirow{3}{*}{$\begin{array}{l}\text { Gajah } \\
\text { Mada }\end{array}$} & 0,330 & B \\
\hline 2 & & 0,707 & $\mathrm{C}$ & & 0,297 & B \\
\hline 3 & & 0,878 & $\mathrm{E}$ & & 0,419 & $\mathrm{C}$ \\
\hline 4 & \multirow{3}{*}{$\begin{array}{l}\text { Panca } \\
\text { Usaha }\end{array}$} & 0,843 & $\mathrm{D}$ & \multirow{3}{*}{$\begin{array}{l}\text { Bung } \\
\text { Karno }\end{array}$} & 0,258 & B \\
\hline 5 & & 0,621 & $\mathrm{C}$ & & 0,246 & B \\
\hline 6 & & 0,712 & $\mathrm{C}$ & & 0,250 & B \\
\hline
\end{tabular}

Sumber : Hasil perhitungan

Kinerja jalan kawasan pendidikan lebih baik dibandingkan dengan jalan kawasan komersial. Jalan kawasan pendidikan memiliki volume kendaraan yang lebih rendah dan kapasitas jalan yang tinggi serta lebar jalur pergerakan kendaraan lebih besar. Sedangkan jalan kawasan komersial memiliki volume kendaraan yang tinggi dan kapasitas jalan yang rendah serta jalur pergerakan kendaraan yang lebih kecil.

\section{PENUTUP}

\section{Simpulan}

1. Jalan kawasan komersial memiliki volume lalu lintas tinggi dan tingkat hambatan samping sangat tinggi (VH). Sedangkan kawasan pendidikan memiliki volume lalu lintas lintas yang rendah dan tingkat hambatan samping sedang (M). Kapasitas jalan kawasan pendidikan lebih tinggi dibandingkan kapasitas jalan kawasan komersial.

2. Hambatan samping berpengaruh sangat signifikan terhadap volume, kapasitas dan derajat kejenuhan jalan kawasan komersial dan kawasan pendidikan. Dapat dilihat dari nilai (r) berada pada rentang 0,7 $<\mathrm{r}<0,9$ menunjukkan korelasi yang kuat dan $0,9<\mathrm{r}<1$ menunjukkan korelasi yang sangat kuat.

3. Kinerja jalan kawasan pendidikan lebih baik dibandingkan jalan kawasan komersial. Derajat Kejenuhan tertinggi jalan kawasan komersial sebesar 0.878 berada pada tingkat pelayanan E. Sedangkan derajat kejenuhan tertinggi jalan kawasan pendidikan sebesar 0.419 berada pada tingkat pelayanan C. 


\section{Saran}

Berdasarkan hasil analisis hambatan samping yang tinggi terutama pada ruas jalan kawasan komersial yang memiliki nilai derajat kejenuhan lebih dari 0.75 sangat mempengaruhi kinerja jalan sehingga dapat disarankan beberapa hal sebagai berikut :

1. Perlu adanya rambu-rambu lalu lintas yang dapat menertibkan lalu lintas seperti tanda larangan parkir pada bahu jalan agar pengguna jalan tidak parkir secara sembarangan.

2. Perlu dilakukan pelebaran jalan untuk meningkatkan kapasitas agar nilai derajat kejenuhan lebih rendah.

3. Perlu adanya aturan dan tindakan dari Pemerintah Kota Mataram untuk menertibkan pedagang kaki lima agar tidak berjualan pada bahu jalan seperti menyediakan lahan khusus untuk PKL agar tidak mempengaruhi arus lalu lintas.

\section{DAFTAR PUSTAKA}

Anonim. (1997). Manual Kapasitas Jalan Indonesia Kapasitas Jalan Perkotaan. Kementerian Pekerjaan Umum.

Aryana, G,W. (2015). Evaluasi Kinerja Ruas Jalan Perkotaan Akibat Hambatan Samping (Studi Kasus Jalan Panca Usaha Kota Mataram). Tugas Akhir. Mataram: Universitas Mataram

Octavia, D. (2020). Pengaruh Hambatan Samping Terhadap Keceptan Volume Dan Tundaan Lalu Lintas Pada Jaringan Jalan Searah Dan Dua Arah Tanpa Median (Studi Kasus Jalan Dr. Wahidin Dan Jalan Catur Warga Kota Mataram). Tugas akhir. Mataram: Universitas Mataram

Prasetyo, E,A. (2017). Evaluasi Kesesuain Penanganan Kinerja Jalan Akibat Hambatan Samping (Studi Kasus Jalan Bung Karno Kota Mataram). Tugas Akhir. Mataram: Univesitas Mataram

Seftiana, R, A. (2019). Analisis Pengaruh Perbedaan Jarak Jalan Akses Dengan U-Turn Terhadap Tingkat Pelanggaran Lalu Lintas (Studi Kasus Jalan Gajah Mada Kota Mataram). Tugas Akhir. Mataram: Univesitas Mataram

Sudjana. (2013). Metoda Statistika. Bandung : Tarsito.

Tamin, O.Z. (2000). Perencanaan Dan Permodelan Transportasi. Bandung : ITB Bandung.

Turyanto. (2014). Kajian Pengaruh Tata Guna Lahan Terhadap Kinerja Jalan Pada Kawasan Pendidikan. Semarang: Universitas Semarang 